\title{
Role of magnetic resonance imaging to detect occult spinal anomalies in anorectal malformations
}

\author{
Prashant Gupta, Umesh K. Gupta, Saugata Ray, Anil Kumar, Somendra Pal Singh*, \\ Shesh Kumar, Mohit Gupta, Praveen Singh, Manas Prakash, Priyansh Sharma
}

Department of Surgery, UP RIMS \& R, Saifai, Etawah, UP, India

Received: 06 March 2016

Revised: 13 March 2016

Accepted: 15 March 2016

\section{*Correspondence:}

Dr. Somendra Pal Singh,

E-mail: somendrachauhan@ @otmail.com

Copyright: ( $)$ the author(s), publisher and licensee Medip Academy. This is an open-access article distributed under the terms of the Creative Commons Attribution Non-Commercial License, which permits unrestricted non-commercial use, distribution, and reproduction in any medium, provided the original work is properly cited.

\section{ABSTRACT}

Background: Anorectal malformations (ARM) are relatively frequently encountered anomalies that represent an important component of pediatric surgical practice. They are a complex group of malformations diagnosed at the time of birth, because of either the absence or an ectopic location of anus. The objective of the study is to determine the incidence of spinal anomalies in all types of anorectal malformations excluding cloaca in this part of country.

Methods: All anorectal malformation patients attending surgery OPD and admitted to Surgery Department of UP RIMS \& R who were completely investigated for associated anomalies during March 2015-Feb 2016 were completely investigated for associated anomalies during the above mentioned period were included in the study.

Results: In our study we found that the incidence of spinal cord anomalies was 3 of 11 (27.2\%) cases with low lesions and 12 of 39 (30.7\%) cases with high lesions had spinal cord anomalies.

Conclusions: MRI evaluation of spine should be performed in all patients of ARM irrespective of type of lesion.

Keywords: Spinal anomalies low type ARM, High type ARM, Anorectal malformations

\section{INTRODUCTION}

Anorectal malformations (ARM) are a complex group of malformations diagnosed at the time of birth because of absence or an ectopic location of bowel end. ${ }^{1-3}$ The incidence is approximated 1:5000 live births and they are more often seen in boys than in girls. ${ }^{4}$

ARM are associated in a high percentage of patients with other anomalies. ${ }^{1,5}$ These anomalies include genitourinary, cardiac, vertebro-spinal and gastrointestinal anomalies. ${ }^{6-9}$ Many of these associated anomalies are serious and the long-term prognosis of child with anorectal malformation is often more dependent on the extent of these associated anomalies than on the anorectal malformation itself.
Literature show that the incidence of spinal cord anomalies was no different between those with a high lesion and those with a low lesion, and spinal cord anomalies were present regardless of vertebral anomalies or symptoms. ${ }^{10,11}$ Therefore, it is recommend for MRI evaluation of all patients with ARM.

\section{Aims \& objectives}

To determine the incidence of spinal anomalies in all types of anorectal malformations excluding cloaca in this part of country.

\section{METHODS}

This study was carried out in the Department of Surgery, UP RIMS \& R, Saifai, Etawah from March 2015-Feb 2016 i.e. 1 year. 
All anorectal malformation patients attending surgery OPD and admitted to Surgery Department of UP RIMS \& $\mathrm{R}$ who were completely investigated for associated anomalies during the above mentioned period were included in the study.

The study population comprised of children less than 12 years of age of both sexes and included all religion with all socioeconomic status.

All patients with ARM admitted in our institute in the above mentioned period were clinically examined systematically for presence of any other co-existing congenital anomaly.

All patients included in this study underwent radiological investigations-USG K.U.B, MCU, X-ray Chest and Lumbo-sacralspine and echocardiography.

All patients in our study underwent a MRI of the lumbosacral spine using a 1.5 Tesla instruments (GE electric) by sequences in $\mathrm{T} 1$ and $\mathrm{T} 2$ with axial, sagittal and coronal scan. Slice thickness varying between 3 to 5 $\mathrm{mm}$.

\section{RESULTS}

This study was conducted in Department of Surgery, UP RIMS \& R from March 2015 to Feb 2016. MRI of the lumbosacral spine was performed in 50 cases of anorectal malformation.

We found that of the 50 cases of ARM who underwent MRI of lumbosacral spine, 26 patients were males and 24 patients were females. Mean age of 3 years at the time of the lumbar MRI (range, 3 months to 11 years old).

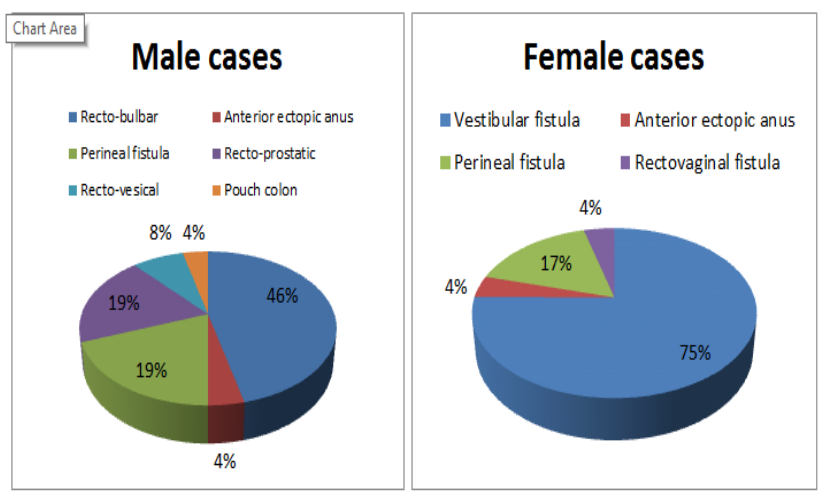

Figure 1: Distribution of different types of ARM in males \& females.

In our study out of the 50 cases which were included, 39 patients had intermediate and high lesions (all defined as high lesions for the purpose of this study) and 11 cases had low level of ARM (according to Melbourne classification).
Among the 39 cases with a high level of ARM, 20 were boys and 19 were girls. Of the 11 cases with low ARM, 6 cases were boys and 5 were girls.

In our study we found that the incidence of Spinal cord anomalies was 3 of $11(27.2 \%)$ cases with low lesions and 12 of $39(30.7 \%)$ cases with high lesions had spinal cord anomalies.

Table 1: Spinal anomalies found in low lesion group.

\begin{tabular}{|ll|}
\hline Low lesions (3) & \\
\hline Spinal lipoma & 2 \\
\hline Unrecognized syringomyelia & 1 \\
\hline
\end{tabular}

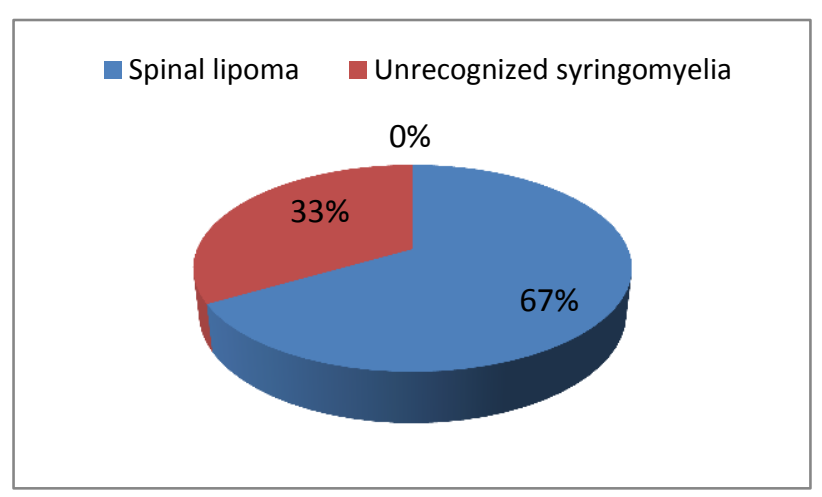

Figure 2: Spinal anomalies in low lesion group.

Table 2: Spinal anomalies found in high lesion group.

\begin{tabular}{|ll|}
\hline High lesions (12) & \\
\hline Spinal lipoma & 6 \\
\hline Unrecognized syringomyelia & 1 \\
\hline Tethered cord & 3 \\
\hline Caudal regression syndrome & 2 \\
\hline
\end{tabular}

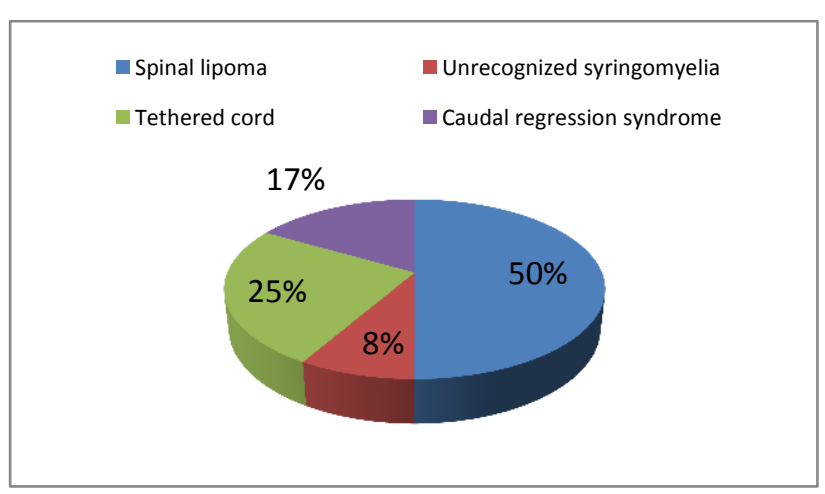

Figure 3: Spinal anomalies in high lesion group.

\section{DISCUSSION}

Our study was carried out in Department of Surgery UP RIMS \& R, Saifai, Etawah from March 2015 to Feb 2016 i.e 1 year. We studied a total number of 50 cases of anorectal malformations who were fully investigated for 
the presence of other associated anomalies. All patients underwent MRI of lumbosacral spine.

The male:female ratio of cases in our study was 23:24, which is comparable to other large studies which had a male to female ratio of $23: 22 .^{12}$

The incidence of high ARM in our study was $78 \%$ while that of low ARM was $22 \%$. This is in contrast to the $26 \%$ incidence of supralevator lesions reported in a large Japanese study. ${ }^{12}$

Incidence of tethered cord in ARM population varied between $10 \%$ to $52 \% .{ }^{13,14}$ In the literature, the incidence of spinal cord anomalies varies from $14 \%$ to $57 \%$ in patients with ARM. ${ }^{11,15}$ In the present study, patients with spinal cord anomalies accounted for $27.2 \%$ (3 of 11 patients) with low lesions and for $30.7 \%$ (12 of 39 patients) with high lesions.

The symptoms found in conjunction with imperforate anus include fecal incontinence, neurovesical dysfunction, gait disturbance and spastic abnormalities of the lower extremities. ${ }^{11}$ Neurovesical dysfunction is primarily related to tethered cord or to an iatrogenic nerve injury. ${ }^{16}$ Once symptoms appear, they are often irreversible despite surgical intervention and may have a significant impact on the continence of patients with imperforate anus. Surgical release of a tethered cord before the onset of neurological problems may prevent the onset of these symptoms. ${ }^{17}$

The influence of a tethered cord on bowel dysfunction remains unknown in patients with ARM. ${ }^{18}$ Recently, Tsuda et $\mathrm{al}^{18}$ reported that bowel function after surgery for ARM did not differ significantly between those with or without a tethered cord. Jia et $\mathrm{al}^{19}$ suggested that the causes of faecal incontinence may be a defect in the sacral parasympathetic nucleus innervation to the rectum during fetal development.

Tuuha et $\mathrm{al}^{20}$ report that the true incidence of tethered cord is approximately $20 \%$ in the setting of ARM. It has been assumed that a tethered cord is more frequent in patients with a high ARM lesion than in those with a low lesion. ${ }^{21}$ Heij et $\mathrm{al}^{22}$ have demonstrated that a tethered cord is more common in patients with a high lesion $(50 \%)$ than in those with a low lesion $(30 \%)$. However, Golonka et $\mathrm{al}^{23}$ reported that a tethered cord in children with a low lesion is as common as in those with a high lesion. Mosiello et $\mathrm{al}^{16}$ reported that the incidence of spinal cord anomalies is $60 \%$ in those with a low lesion and $66 \%$ in those with a high lesion. In the present study, spinal cord anomalies were identified in $30 \%$ (15 of 50 patients) and vertebral column anomalies in $40 \%$ (20 of 50 patients). Spinal cord anomalies were reported in $27.2 \%$ with low lesions and $30.7 \%$ with high lesions. Most common spinal cord anomaly was spinal lipoma$16 \%$ ( 8 of 50 patients) followed by tethered cord- $6 \%$ (3 of 50 patients). All patients with tethered cord were in high lesion group. Incidence of tethered cord was low in our study because we excluded all cloaca patients.

Some authors recommend MRI evaluation of all patients with ARM because spinal cord anomalies, including a tethered cord, are known to occur in patients without vertebral anomalies as well as in those with a low ARM. ${ }^{10,11,14,20-22}$ Our results show that the incidence of spinal cord anomalies was no different between those with a high lesion and those with a low lesion and spinal cord anomalies were present regardless of vertebral anomalies or symptoms. Therefore, we also recommend MRI evaluation of all patients with ARM.

Consideration should also be given to USG as a noninvasive method that is also less expensive than MRI. As such, USG is an ideal screening tool for infants younger than 3 months. USG is recommended for screening infants younger than 3 months with an imperforate anus, followed by MRI to confirm abnormal findings. ${ }^{13}$ However, with USG it is often difficult to evaluate spinal cord anomalies in patients with vertebral anomalies and in older children. ${ }^{16}$ Our study did not include USG to evaluate lumbosacral spine because all our patients were older than 3 months. Mosiello et al ${ }^{16}$ recommended that MRI screening at the age of 6-12 months for all patients with an imperforate anus. MRI is the most sensitive modality for detecting spinal cord anomalies, as well as for detecting vertebral anomalies.

In our study Down's syndrome was seen in 1 patient. The parents of this patient need to undergo genetic counseling, to explain the risk of similar disease in future children.

CNS anomalies that are correctable like hydrocephalus (1 in our series) need to be evaluated by a neurosurgeon and dealt with accordingly. Uncorrectable CNS anomalies like cerebral atrophy ( 1 in our series) have a poor quality of life and this need to be explained to the parents.

Limitation of our study is that, it is a small series and carried out in a single center. Therefore, a larger, multicentric, prospective study is necessary.

\section{CONCLUSION}

MRI evaluation of spine should be performed in all patients of ARM irrespective of type of lesion.

\section{Funding: No funding sources \\ Conflict of interest: None declared \\ Ethical approval: The study was approved by the Institutional Ethics Committee}

\section{REFERENCES}

1. Mittal A, Airon RK, Magu S, Rattan KN, Ratan SK. Associated anomalies with anorectal malformation. Indian J Pediatr. 2004;71:509-14. 
2. Ratan SK, Rattan KN, Pandey RM, Mittal A, Magu S, Sodhi PK. Associated congenital anomalies in patients with anorectal malformations-a need for developing a uniform practical approach. J Pediatr Surg. 2004;39:1706-11.

3. Partridge JP, Crough MH. Congenital abnormalities of anus and rectum. Br J Surg. 1961;49:37.

4. Boocock GR, Donnai D. Anorectal malformation: familial aspects and associated anomalies. Arch Dis Child. 1987;62:576-9.

5. Hassink EA, Rieu PN, Hamel BC, Severijnen RS, vd Staak FH, Festen C. Additional congenital defects in anorectal malformations. Eur J Pediatr. 1996;155(6):477-82.

6. Vaishali S, Ray AK, Patra R, Saha Basu K, Samanta N., Saha K. Urogenital anomalies associated with anorectal malformations. J Indian Assoc Pediatr Surg. 2005;10(1):44-7.

7. Karrer FM, Flannery AM, Nelson MD Jr, McLone DG, Raffensperger JG. Anorectal malformations: evaluation of associated spinal dysraphic syndrome.J Pediatr Surg. 1988;23:45-8.

8. Hoekstra WJ, Scholtmeijer RJ, Molenaar JC, Schreeve, RH, Schroeder FH. Urogenital tract abnormalities associated with congenital anorectal anomalies. J Urol. 1983;130:962-3.

9. Teixeira HO, Malhotra K, Sellers J, Mercer S. Cardiovascular anomalies with imperforate anus. Arch Dis Child. 1983;58:747-9.

10. Nievelstein RA, Vos A, Valk J. MR imaging of anorectal malformations and associated anomalies. Eur Radiol. 1998;8:573-81.

11. De Gennaro M, Rivosecchi M, Lucchetti MC, Silveri M, Fariello G, Schingo P. The incidence of occult spinal dysraphism and the onset of neurovesical dysfunction in children with anorectal anomalies. Eur J Pediatr Surg. 1994;4(1):12-4.

12. Endo M, Hayashi A, Ishihara M, Maie M, Nagasaki A, Nishi T, Saeki M. Analysis of 1,992 patients with anorectal malformations over the past two decades in Japan. Steering committee of Japanese study group of anorectal anomalies. J Pediatr Surg. 1999;34:435-41.

13. Long FR, Hunter JV, Mahboubi S, Kalmus A, Templeton JM Jr. Tethered cord and associated vertebral anomalies in children and infants with imperforate anus: evaluation with MR imaging and plain radiography. Radiology. 1996;200(2):377-82.

14. Morimoto K, Takemoto O, Wakayama A. Tethered cord association with anorectal malformation. Pediatr Neurosurg. 2003;38:79-82.

15. Nievelstein RA, Vos A, Valk J, Vermeij-Keers C. Magnetic resonance imaging in children with anorectal malformations: embryologic implications. J Pediatr Surg. 2002;37(8):1138-45.

16. Mosiello G, Capitanucci ML, Gatti C, Adorisio O, Lucchetti MC, Silveri M et al. How to investigate neurovesical dysfunction in children with anorectal malformations. J Urol. 2003;170:1610-3.

17. Hsieh MH, Perry V, Gupta N, Pearson C, Nguyen HT. The effects of detethering on the urodynamics profile in children with a tethered cord. J Neurosurg. 2006;105(5):391-5.

18. Tsuda T, Iwai N, Kimura O, Kubota Y, Ono S, Sasaki Y. Bowel function after surgery for anorectal malformations in patients with tethered spinal cord. Pediatr Surg Int. 2007;23(12):1171-4.

19. Jia H, Zhang K, Zhang S, Yuan Z, Bai Y, Wang W. Quantitative analysis of sacral parasympathetic nucleus innervating the rectum in rats with anorectal malformation. J Pediatr Surg. 2007;42(9):1544-8.

20. Tuuha SE, Aziz D, Drake J, Wales P, Kim PC. Is surgery necessary for asymptomatic tethered cord in anorectal malformation patients? J Pediatr Surg. 2004;39(5):773-7.

21. Leonidas JC, Singh SP, Slovis TL. Anomalies of the colon and anorectal area. In: Kuhn JP, Slovis TL, Haller JO (eds) Caffey's pediatric diagnostic imaging. $10^{\text {th }}$ edn. Mosby, Philadelphia; 2004:140149.

22. Heij HA, Nievelstein RA, de Zwart I, Verbeeten B WJ M, Valk J, Vos A. Abnormal anatomy of the lumbosacral region imaged by magnetic resonance in children with anorectal malformations. Arch Dis Child. 1996;74:441-4.

23. Golonka NR, Haga LJ, Keating RP, Eichelberger MR, Gilbert JC, Hartman GE et al. Routine MRI evaluation of low imperforate anus reveals unexpected high incidence of tethered spinal cord. J Pediatr Surg. 2002;37:966-69.

Cite this article as: Gupta K, Gupta UK, Ray S, Kumar A, Singh SP, Kumar S, Gupta M, Singh P, Prakash M, Sharma P. Role of magnetic resonance imaging to detect occult spinal anomalies in anorectal malformations. Int J Contemp Pediatr 2016;3:491-4. 